\title{
HRPU-2, a Homolog of Mammalian hnRNP U, Regulates Synaptic Transmission by Controlling the Expression of SL0-2 Potassium Channel in Caenorhabditis elegans
}

\author{
Ping Liu, ${ }^{1}$ Sijie Jason Wang, ${ }^{2}{ }^{-Z h a o-W e n ~ W a n g, ~}{ }^{1}$ and ${ }^{\circledR}$ Bojun Chen ${ }^{1}$ \\ ${ }^{1}$ Department of Neuroscience, UConn Health, Farmington Connecticut 06030-3401, and ${ }^{2}$ Department of Hospital Medicine, Concord Hospital, Concord, \\ New Hampshire 03301
}

Slo2 channels are large-conductance potassium channels abundantly expressed in the nervous system. However, it is unclear how their expression level in neurons is regulated. Here we report that HRPU-2, an RNA-binding protein homologous to mammalian heterogeneous nuclear ribonucleoprotein $\mathrm{U}(\mathrm{hnRNP} \mathrm{U})$, plays an important role in regulating the expression of SLO-2 (a homolog of mammalian Slo2) in Caenorhabditis elegans. Loss-of-function ( $l f)$ mutants of $h r p u-2$ were isolated in a genetic screen for suppressors of a sluggish phenotype caused by a hyperactive SLO-2. In $h r p u-2(l f)$ mutants, SLO-2-mediated delayed outward currents in neurons are greatly decreased, and neuromuscular synaptic transmission is enhanced. These mutant phenotypes can be rescued by expressing wild-type HRPU-2 in neurons. HRPU-2 binds to slo-2 mRNA, and hrpu-2(lf) mutants show decreased SLO-2 protein expression. In contrast, hrpu-2(lf) does not alter the expression of either the BK channel SLO-1 or the Shaker type potassium channel SHK-1. hrpu-2(lf) mutants are indistinguishable from wild type in gross motor neuron morphology and locomotion behavior. Together, these observations suggest that HRPU-2 plays important roles in SLO-2 function by regulating SLO-2 protein expression, and that SLO-2 is likely among a restricted set of proteins regulated by HRPU-2. Mutations of human Slo2 channel and hnRNP U are strongly linked to epileptic disorders and intellectual disability. The findings of this study suggest a potential link between these two molecules in human patients.

Key words: C. elegans; hnRNP U; HRPU-2; SLO-2; synaptic transmission

\section{Significance Statement}

Heterogeneous nuclear ribonucleoprotein $\mathrm{U}$ (hnRNP U) belongs to a family of RNA-binding proteins that play important roles in controlling gene expression. Recent studies have established a strong link between mutations of hnRNP $\mathrm{U}$ and human epilepsies and intellectual disability. However, it is unclear how mutations of hnRNP U may cause such disorders. This study shows that mutations of HRPU-2, a worm homolog of mammalian hnRNP U, result in dysfunction of a Slo2 potassium channel, which is critical to neuronal function. Because mutations of Slo2 channels are also strongly associated with epileptic encephalopathies and intellectual disability in humans, the findings of this study point to a potential mechanism underlying neurological disorders caused by hnRNP U mutations.

\section{Introduction}

Slo2 channels are a family of large-conductance potassium channels found in mammals and invertebrates. Humans and mice

Received July 13, 2017; revised Nov. 27, 2017; accepted Dec. 2, 2017.

Author contributions: Z.-W.W. and B.C. designed research; P.L. and B.C. performed research; S.J.W. contributed unpublished reagents/analytic tools; P.L., S.J.W., and B.C. analyzed data; Z.-W.W. and B.C. wrote the paper.

This work was supported by National Institutes of Health Grants R01-GM-113004 (to B.C.) and 2R01-MH-085927 (to Z.-W.W.). We thank Erik M. Jorgensen and the Caenorhabditis Genetics Center (College of Biological Sciences, University of Minnesota, Saint Paul, MN) for worm strains, and Kaijie J. Wang for critical reading.

The authors declare no competing financial interests.

Correspondence should be addressed to Dr. Bojun Chen, Department of Neuroscience, UConn Health, 263 Farmington Avenue, Farmington, CT 06030-3401. E-mail: bochen@uchc.edu.

DOI:10.1523/JNEUROSCI.1991-17.2017

Copyright $\odot 2018$ the authors $\quad 0270-6474 / 18 / 381073-12 \$ 15.00 / 0$ each have the following two Slo2 channels: Slo2.1/Slick and Slo2.2/Slack (Kaczmarek, 2013). Both channels are widely expressed in the nervous system (Bhattacharjee et al., 2002, 2005; www.brain-map.org), where Slack is a major contributor to delayed outward currents in a variety of neurons examined (Budelli et al., 2009; Lu et al., 2010; Martinez-Espinosa et al., 2015). Mutations of Slack in humans are strongly associated with epileptic encephalopathies and intellectual disability (Barcia et al., 2012; Heron et al., 2012; Ishii et al., 2013; Martin et al., 2014; Vanderver et al., 2014). Knockout of Slack in mice causes hyperexcitability of neurons, enhanced pain and itch responses, and cognitive impairment (Bausch et al., 2015; Lu et al., 2015; Martinez-Espinosa et al., 2015). These findings suggest that Slo2 channels, especially 
Slack, have important physiological functions in the nervous system.

It is well recognized that the proper function of a potassium channel in vivo generally depends on many interacting proteins. For example, studies of the BK channel Slo1, which is a paralogue of Slo2, have identified a variety of interacting proteins that regulate various aspects of Slo1 biology, including expression, membrane trafficking, voltage dependence, activation and inactivation rates, and subcellular localization (Schopperle et al., 1998; Xia et al., 1998; Zhou et al., 1999; Kim et al., 2009; Abraham et al., 2010; Chen et al., 2010a, b; Contreras et al., 2012; Li and Yan, 2016). In contrast, aside from some general ion channel regulators [e.g., protein kinases, cAMP, and PIP2 (phosphatidylinositol 4,5-bisphosphate)], only a single protein, the mRNA-binding protein fragile X mental retardation protein (FMRP), has been identified as a regulatory protein for Slo2 (Kaczmarek, 2013). FMRP can bind to Slack C terminal to enhance channel activity, and a lack of FMRP compromises Slack-mediated outward currents in neurons without reducing Slack protein expression (Brown et al., 2010). In Aplasia bag cells, where FMRP also regulates Slack, knockdown of Slack prevents recovery from a prolonged inhibitory period that normally follows an evoked discharge of action potentials. This action is replicated by treatment with a protein synthesis inhibitor, which has led to the suggestion that interactions between Slack and FMRP may link changes in neuronal firing to changes in protein translation (Zhang et al., 2012).

Heterogeneous nuclear ribonucleoproteins (hnRNPs) comprise a family of RNA-binding proteins with 20 members in humans. They exist predominantly in the nucleus but can translocate to the cytosol (Han et al., 2010; Geuens et al., 2016). hnRNP U is the largest in size among this family of proteins. Prominent structural domains of hnRNP $\mathrm{U}$ include an $\mathrm{N}$ terminal rich in acidic residues and a C-terminal arginine-glycine-glycine (RGG) box, which contains a cluster of RGG repeats and mediates RNA binding (Kiledjian and Dreyfuss, 1992). Documented roles of hnRNP $\mathrm{U}$ include the regulation of gene transcription (Spraggon et al., 2007; Matsuoka et al., 2009; Vizlin-Hodzic et al., 2011), excision of introns and alternative axons from precursor mRNA (Xiao et al., 2012; Wee et al., 2014; Ye et al., 2015), and maintenance of RNA stability (Yugami et al., 2007). As with mutations of Slack, mutations of hnRNP $U$ are strongly linked to epileptic encephalopathies and intellectual disability (Carvill et al., 2013; Allen et al., 2013; Hamdan et al., 2014; de Kovel et al., 2016; Bramswig et al., 2017; Depienne et al., 2017). However, it is unclear whether such disorders caused by hnRNP U mutations are related to Slo2 function. Despite their important roles in protein expression, hnRNPs have been rarely implicated in regulating the expression of ion channels (Ferron et al., 2008; Liu et al., 2012).

The nematode Caenorhabditis elegans has a single Slo2 homolog known as SLO-2. It is a predominant conductor of delayed outward currents in neurons and muscle cells. Loss-of-function (lf) mutation of slo-2 causes elevated (less hyperpolarized) resting membrane potential in neurons and muscle cells, increased neurotransmitter release from neurons, and broadened action potentials and diminished afterhyperpolarization in muscle cells (Liu et al., 2011, 2014). We hypothesized that there are unidentified proteins critical to Slo2 expression or function in vivo and embarked on a project to identify them using a forward genetic approach with C. elegans. Here we report the discovery of HRPU-2, a homolog of mammalian hnRNP U, as an important regulator of SLO-2 expression in vivo. Our findings may facilitate the understanding of the molecular bases of diseases caused by mutations of hnRNP U and Slo2 in humans.

\section{Materials and Methods}

C. elegans culture and strains. C. elegans hermaphrodites were raised on nematode growth medium plates spotted with a layer of OP50 Escherichia coli at $22^{\circ} \mathrm{C}$ inside an environmental chamber. The following strains were used in this study (plasmids used in making the transgenic strains are indicated by numbers with a " $w p$ " prefix): wild-type (Bristol N2): LY101, slo-2(nf101); ZW083, zwIs101[Pslo-1::slo-1::GFP (wp5)]; ZW236, oxIs215[Punc-47::mRFP]; ZW860, zwIs[Pslo-1::slo-2(gf)(wp1311), Pmyo-2:: YFP(wp214)]; ZW798, zwIs133[Punc-17::GFP(wp608)]; ZW861, zwIs[Pslo1::slo-2(gf)(wp1311), Pmyo-2::YFP(wp214)]; hrpu-2(zw65); ZW866, zwIs [Pslo-1::slo-2(gf)(wp1311), Pmyo-2::YFP(wp214)]; hrpu-2(zw70); ZW871, zwIs[Pslo-1::slo-2(gf)(wp1311), Pmyo-2::YFP(wp214)]; hrpu-2(zw75); ZW915, slo-2(nf101); hrpu-2(zw65). ZW1004: slo-2(nf101); hrpu-2(zw75); ZW1020, zwIs[Prab-3::hrpu-2::GFP(wp1370)]; ZW1047, zwEx219[Prab-3::hrpu-2:: GFP(wp1370), hrpu-2(zw65)]; ZW1048, zwEx220[Phrpu-2::GFP(wp1372), lin-15(+)]; lin-15(n765); ZW1049, zwEx221[Prab-3::slo-2::GFP]; ZW1050, zwEx221[Prab-3::slo-2::GFP]; hrpu-2(zw65);ZW1051, zwEx221[Prab-3::slo2::GFP]; hrpu-2(zw75); ZW1061, zwIs101[Pslo-1::slo-1::GFP (wp5)]; hrpu2(zw65); ZW1083, zwIs133[Punc-17::GFP(wp608)]; hrpu-2(zw65); ZW1084, oxIs215[Punc-47::mRFP]; hrpu-2(zw65); ZW1091, zwEx229[Pslo-1::slo-2 (wp1090); slo-2(nf101); ZW1092, zwEx230[Pslo-1::slo-2(wp1311); slo-2 (nf101); ZW1096, zwEx231[Prab-3::His-58::mStrawberry(p1749), Prab-3:: hrpu-2::GFP(p1370), lin-15(+)]; lin-15(n765); ZW1147, zwIs139[Pslo-1:: slo-2(gf)(wp1311), Pmyo-2::YFP(wp214)]; zwEx246[Prab-3::hrpu-2(wp1738), Prab-3::GFP(wp70)]; hrpu-2(zw65); ZW1149, zwEx247[Pslo-2::mStrawberry (wp1776), lin-15(+)];zwEx220[Phrpu-2::GFP(wp1372), lin-15(+)]; lin-15 (n765);ZW1151, zwEx248[Pmyo-3::slo-2::GFP(wp1319);ZW1152, zwEx248 [Pmyo-3::slo-2::GFP(wp1319); hrpu-2(zw65); ZW1153, zwEx248[Pmyo-3:: slo-2::GFP(wp1319); hrpu-2(zw75); ZW1159, zwEx253[Prab-3::shk1::GFP(wp1770)]. ZW1160: zwEx253[Prab-3::shk-1::GFP(wp1770)]; hrpu-2(zw65).

Mutant screening and mapping. An integrated transgenic strain expressing Pslo-1::SLO-2(gf) and Pmyo-2::YFP in the wild-type genetic background was used for mutant screen. Pmyo-2::YFP, which expresses YFP (yellow fluorescent protein) in the pharynx, served as a genetic marker. Synchronized L4-stage slo-2(gf) worms were treated with the chemical mutagen ethyl methanesulfonate $(50 \mathrm{~mm})$ for $4 \mathrm{~h}$ at room temperature. F2 progeny of the mutagenized worms were screened for animals that moved better than the original slo-2 $(g f)$ worms. Seventeen suppressors were isolated in the screen and were subjected to whole-genome sequencing. Analysis of the whole-genome sequencing data showed that nine mutants have mutations in $h r p u-2$ (www.wormbase.org). Expression of a wild-type cDNA of hrpu-2 under the control of Pslo-1 in slo-2(gf); hrpu$2(z w 65)$ double mutants fully reinstated the lethargic phenotype.

Analysis of locomotion behavior. Locomotion velocity was quantified using Track-A-Worm, an automated worm-tracking and analysis system (Wang and Wang, 2013). Briefly, a single young adult hermaphrodite was transferred to a nematode growth media plate without food. After an $\sim 30$ s recovery time from the transfer, snapshots of the worm were taken at 3 frames/s for 1 min using a VGA FireWire camera (XCD-V60, Sony) mounted on a stereomicroscope (SMZ800, Nikon). The worm was constantly kept in the center of the view field with a motorized microscope stage (OptiScanTM ES111, Prior Scientific). Both the camera and motorized stage were controlled by Track-A-Worm.

Analysis of expression pattern and subcellular localization. The expression pattern of $h r p u-2$ was assessed by expressing GFP under the control of $3.1 \mathrm{~kb} h r p u-2$ promoter (Phrpu-2::GFP, wp1372). Primers for cloning Phrpu-2 were 5'-GAAGCTGCAGCCACCAAACTCCACATGC (forward) and 5' -TTTACCGGTTCGTCGGTCATTTTTATTGAG (reverse). Subcellular localization of HRPU-2 was determined by fusing GFP to its $\mathrm{C}$ terminus and expressing the fusion protein under the control of Prab-3 (Prab-3::hrpu-2::GFP, wp1370). Primers for cloning $h r p u-2$ cDNA are 5'-CTTAGTCGACACGATGACCGACGAGACTGAAAAT (forward) and 5'-TTTACCGGTCCGTAGCGACGGCGTTCAAAGA (reverse). A plasmid (wp1749) harboring Prab-3::his-58::mStrawberry was constructed to serve as a nucleus marker. Primers for cloning his-58 cDNA are 5' -TAAGGTACCATGCCACCAAAGCCATCTGC (forward) and 5' ATAGCTAGCTTACTTGCTGGAAGTGTACTTGG (reverse). The plas- 
A

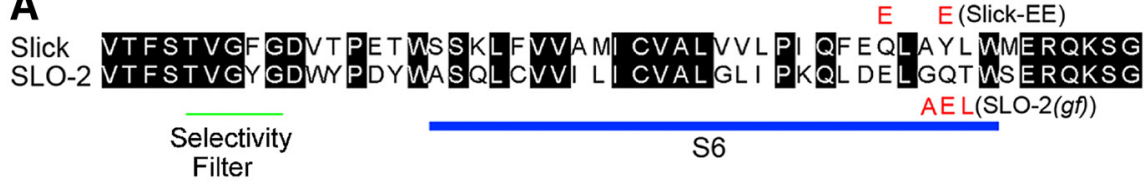

B

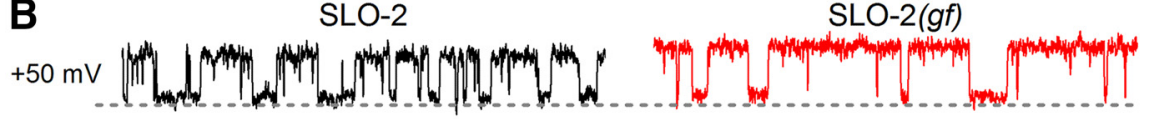

+30 mV ANH

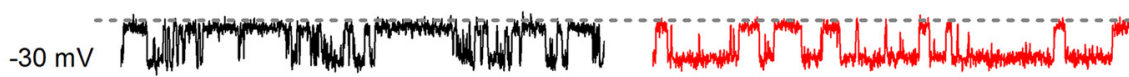
$-50 \mathrm{mV}$

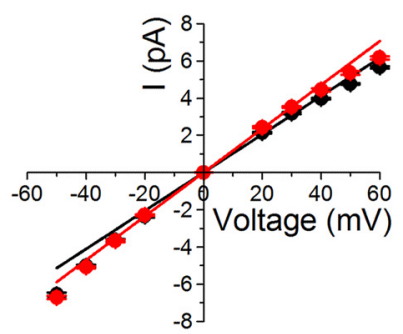

C

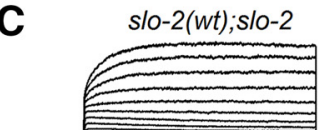
slo-2(gf);slo-2
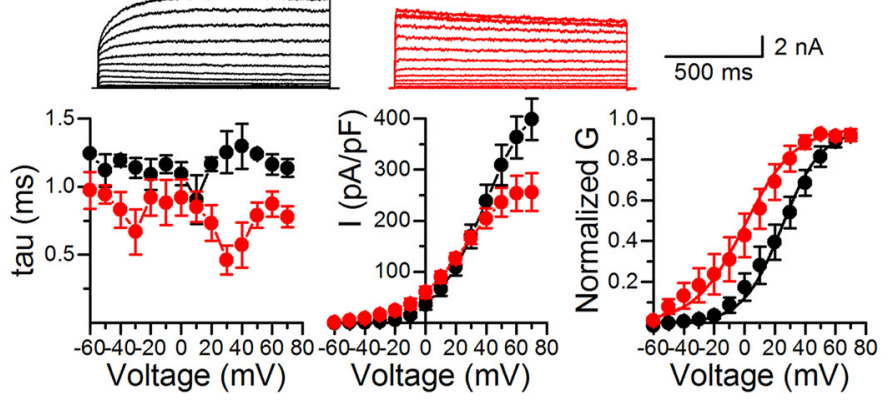

Voltage $(\mathrm{mV})$
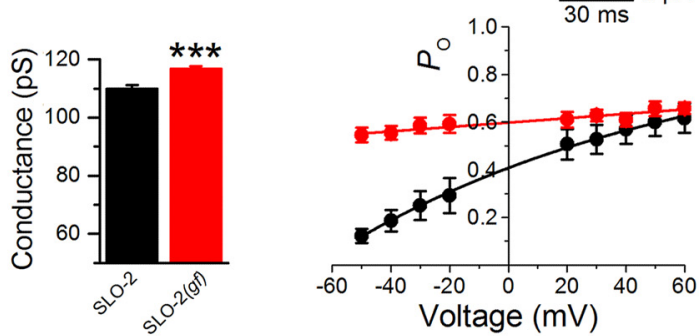

verted Microscope equipped with EGFP/FITC and mCherry/Texas Red filter sets (49002 and 49008, Chroma Technology).

Electrophysiology. Adult hermaphrodites were used in all electrophysiological experiments. Worms were immobilized and dissected as described previously (Liu et al., 2013). Borosilicate glass pipettes were used as electrodes for recording whole-cell currents. Pipette tip resistance for recording muscle cell currents was 3-5 $\mathrm{M} \Omega$, whereas that for recording motor neuron currents was $\sim 20 \mathrm{M} \Omega$. The dissected worm preparation was treated briefly with collagenase and perfused with the extracellular solution for 5-fold to 10-fold of bath volume. Classical whole-cell configuration was obtained by applying a negative pressure to the recording pipette. Current-clamp and voltage-clamp experiments were performed with a Multiclamp 700B amplifier (Molecular Devices) and the Clampex software (version 10, Molecular Devices). Data were sampled at a rate of $10 \mathrm{kHz}$ after filtering at $2 \mathrm{kHz}$. Spontaneous membrane potential changes were recorded using the current-clamp technique without current injection. Motor neuron whole-cell outward currents were recorded by applying a series of voltage steps $(-60$ to $+70 \mathrm{mV}$ at $10 \mathrm{mV}$ intervals; $1200 \mathrm{~ms}$ pulse duration) from a holding potential of $-60 \mathrm{mV}$. Spontaneous postsynaptic currents (PSCs) were recorded from bodywall muscle cells at a holding potential of -60 $\mathrm{mV}$. Two bath solutions and three pipette solutions were used in electrophysiological experiments, as specified in figure legends. Bath solution I contained the following (in mM): 140 $\mathrm{NaCl}, 5 \mathrm{KCl}, 5 \mathrm{CaCl}_{2}, 5 \mathrm{MgCl}_{2}, 11$ dextrose, and 5 HEPES, pH 7.2. Bath solution II contained the following (in mM): $100 \mathrm{~K}^{+}$gluconate, $50 \mathrm{KCl}$, $1 \mathrm{Mg}^{2+}$ gluconate, $0.1 \mathrm{Ca}^{2+}$ gluconate, and 10 HEPES, pH 7.2. Pipette solution I contained the following (in mM): $120 \mathrm{KCl}, 20 \mathrm{KOH}, 5$ Tris, 0.25 $\mathrm{CaCl}_{2}, 4 \mathrm{MgCl}_{2}, 36$ sucrose, 5 EGTA, and 4 $\mathrm{Na}_{2} \mathrm{ATP}, \mathrm{pH}$ 7.2. Pipette solution II differed from pipette solution I in that $113.2 \mathrm{KCl}$ was substituted by $\mathrm{K}^{+}$gluconate. Pipette solution III contained the following (in $\mathrm{mM}$ ): $150 \mathrm{~K}^{+}$gluconate, $1 \mathrm{Mg}^{2+}$ gluconate, and $10 \mathrm{HEPES}(\mathrm{pH} 7.2$ ).

Quantification of SLO-2::GFP fluorescence intensity. Young adult worms expressing Prab3::SLO-2::GFP were immobilized in M9 solution containing $1 \mathrm{~mm}$ azide. Images of the ventral nerve cords posterior to the vulva or the body-wall muscle cells were obtained using the Hamamatsu digital CMOS camera with an mids were injected into the lin-15(n765) strain along with a lin-15 rescue plasmid to serve as a transformation marker. To determine whether hrpu-2 is coexpressed with slo-2, two genomic fragments (5.3 and $5.5 \mathrm{~kb}$ with $0.6 \mathrm{~kb}$ overlap) upstream of a common exon of slo- 2 were amplified by PCR using the following primers: 5' -TTCATGCGCGAACAGGATCA (forward) and 5'-AACAATCAGAGGGCCTTTGGTAG (reverse; 5.3 $\mathrm{kb}$ ); and 5'-ATACTGCAGGATCCACCTCCTCACATTCACTGA (forward) and 5'-GAAACCGGTCCATACTGCATCCGAGCACTG (reverse; $5.5 \mathrm{~kb}$ ). The $5.5 \mathrm{~kb}$ fragment was cloned into a plasmid containing mStrawberry, and the resultant plasmid (wp1776) was linearized and coinjected with the $5.3 \mathrm{~kb}$ fragment into the lin-15(n765) strain. A Pslo-2:: mStrawberry transgene thus generated was subsequently crossed into the strain expressing Phrpu-2::GFP. Images of transgenic worms were taken with a digital CMOS (complementary metal-oxide semiconductor) camera (C11440-22CU, Hamamatsu) mounted on a Nikon TE2000-U In- identical exposure time for each groups. ImageJ software was used to extract straightened ventral cord images and to quantify fluorescence intensity. For each image, SLO-2::GFP intensity was calculated by subtracting the minimum intensity (background fluorescence) from the average intensity.

Expression of SLO-1::GFP and SHK-1::GFP fusion proteins. To compare slo-1 expression between wild-type and $h r p u-2$ mutants, an integrated Pslo-1::slo-1::GFP transgene (Chen et al., 2011) was crossed into the hrpu-1(zw65) strain. To compare shk-1 expression between wild-type and $h r p u-2$ mutant, a shk-1 cDNA was cloned and inserted before GFP in an existing plasmid containing Prab-3::GFP. Primers for cloning shk-1 were 5 '-ATTGGATCCATGCGATTCGGTGGTCAACG (forward) and 5'-TGTGCCGGCGCGATGTCGTCGTCTGCAT (reverse). The Prab-3:: shk-1::GFP plasmid (wp1770) was first injected into wild-type worms to create a stable transgenic line, and then the transgene was crossed into 
A
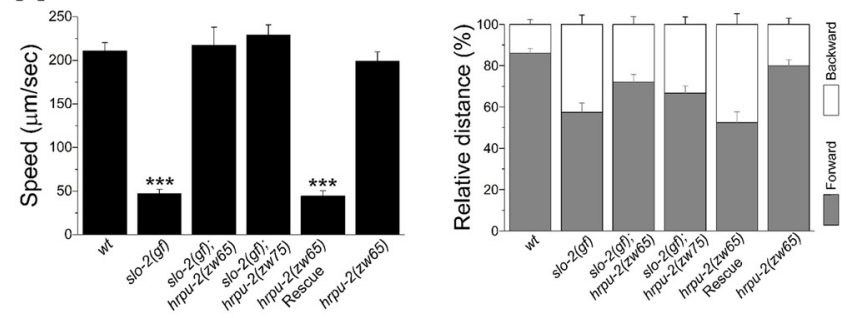

B

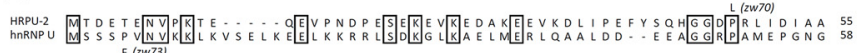

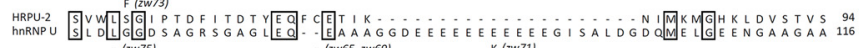

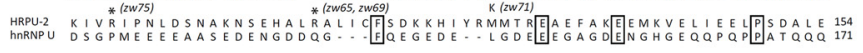

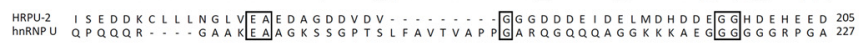

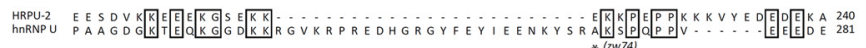

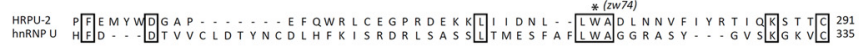

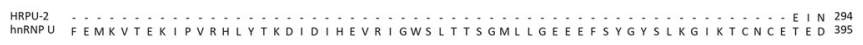

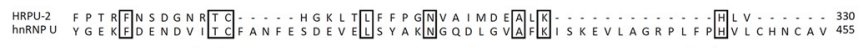

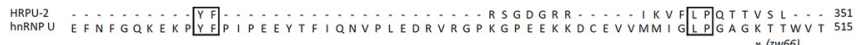

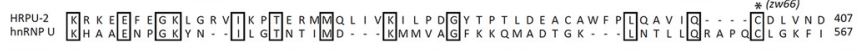

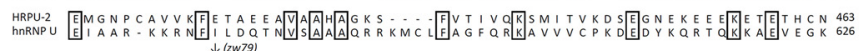

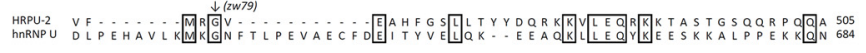

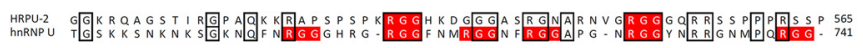

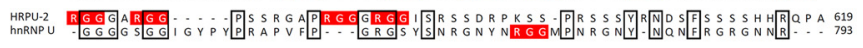
HPPU.

C

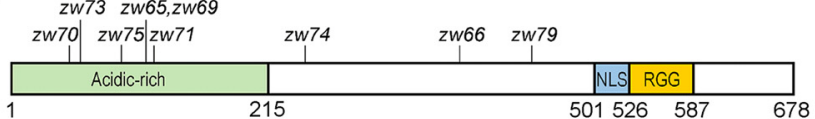

D
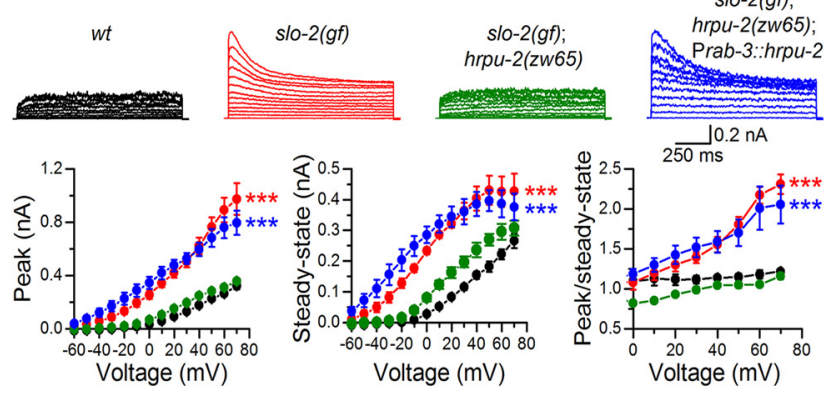

E
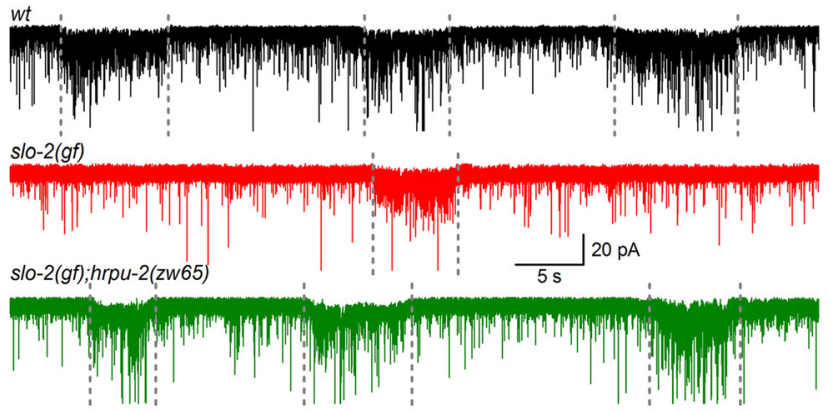

slo-2(gf); $h r p u-2(z w 65) ; P r a b-3:: h r p u-2$
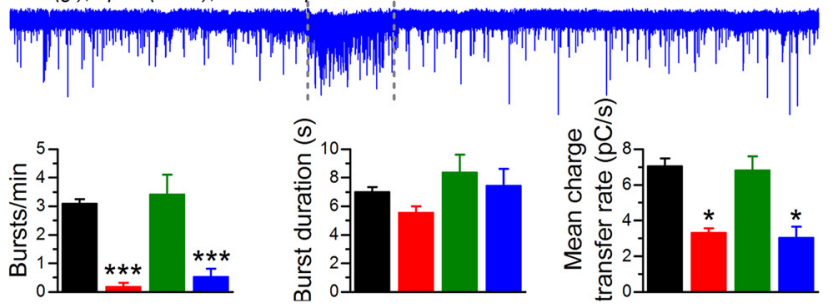

Figure 2. Mutations of $h r p u-2$ suppress the sluggish phenotype of $5 / 0-2(g f)$. A, Comparison of locomotion speed (left) and the percentage of forward and backward locomotion (right) among different worm strains. The sample size was $10-12$ for each group. The asterisks $\left.{ }^{(* *}\right)$ indicate a significant difference compared with wild type (wt; $p<0.001$, one-way ANOVA with Tukey's post hoc tests). $\boldsymbol{B}$, Alignment of amino acid sequences between HRPU-2b and the human hnRNPU (NP_114032). Identical residues are in black boxes. RGG repeats are shaded in red. The molecular lesions of the isolated $h r p u-2$ mutants are indicated above the sequence. Among the nine hrpu-2 mutants, five have nonsense mutations (marked by *):zw75(R98.), zw65 and zw69 (R114.), zw74(W273.), and zw66(C402.); three have missense mutations: $2 w 70(\mathrm{P} 48 \mathrm{~L}), z w 73(\mathrm{S60F})$, and zw71(M128K); and one has a mutation at the splicing junction of the eighth intron leading to a frame shift after G468 (marked by an arrow). C, Schematic diagram of HRPU-2 domain structure and locations of the mutations in different $h r p u-2$ mutant alleles. HRPU-2 has an acidic-rich region at the amino terminal, and a nuclear localization signal (NLS) and an RGG domain at the C terminal. The NLS was identified using cNLS mapper (nls-mapper.iab.keio.ac.jp/). D, hrpu-2(zw65) reverses the effects of slo-2(gf) on whole-cell currents in VA5 motor neuron, and these effects are restored by the expression of the wild-type hrpu-2 in neurons of slo-2(gf);hrpu-2(zw65) (Rescue). The sample sizes were 6 wt, 5 slo-2(gf), 6slo-2(gf); $h r p u-2(z w 65)$, and 7 Rescue. Pipette solution I and bath solution I were used. The asterisks $\left({ }^{* * *}\right)$ indicate a significant difference compared with slo-2(gf) $(p<0.001$, two-way ANOVA with Tukey's post hoc tests). E, hrpu-2(zw65) suppresses inhibitory effects of $5 / 0-2(g f)$ on the frequency and mean charge transfer of PSC bursts, and these effects are restored by expression of the wild-type $h r p u-2$ in neurons of slo-2(gf); hrpu-2(zw65) (Rescue). Shown are representative traces of spontaneous PSCs and the comparison of PSC burst properties. The vertical dotted lines mark PSC bursts, which are defined as an apparent increase in PSC frequency accompanied by a baseline drop lasting $>3 \mathrm{~s}$. The sample sizes were $7 \mathrm{wt}, 6 \mathrm{slo}-2(\mathrm{gf}), 7 \mathrm{slo}-2(\mathrm{gf})$ ), $h r p u-2(z \mathrm{w} 65)$, and 8 Rescue. Pipette solution II and bath solution I were used. The asterisks indicate a statistically significant difference compared with slo-2(gf) $\left({ }^{*} p<0.05\right.$; ${ }^{* * *} p<0.001$, one-way ANOVA with Tukey's post hoc tests).

hrpu-2(zw65). Images of the ventral nerve cord of the transgenic worms were taken as described above.

$R N A$ isolation and quantitative reverse transcription-PCR. Total RNA was extracted from synchronized adult-stage worms using TRIzol Reagent (Invitrogen) and treated with TURBO DNase (Ambion). One microgram of total RNA was reverse transcribed with M-MuLV reverse transcriptase (New England BioLabs) using oligo $(\mathrm{dT})_{16}$ primer. Quantitative real-time PCR was performed in a $20 \mu \mathrm{l}$ volume using iTaq Universal SYBR Green Supermix (Bio-Rad) on CFX Real-Time PCR Detection System (Bio-Rad). The amplification was performed as follows: $3 \mathrm{~min}$ at $95^{\circ} \mathrm{C}$ for initial polymerase activation, 40 cycles of $10 \mathrm{~s}$ at $95^{\circ} \mathrm{C}$ for denaturation and $30 \mathrm{~s}$ at $62^{\circ} \mathrm{C}$ for annealing and extension, and a final melting curve stage from $65^{\circ} \mathrm{C}$ to $95^{\circ} \mathrm{C}$ to verify the specificity of amplicons. The relative amounts of mRNA were determined using the Comparative $\mathrm{Ct}$ method and presented as the fold change relative to control. Quantitative reverse transcription-PCR (qRT-PCR) was performed in triplicate, and each sample was independently normalized to the endogenous reference gene act-1. Primers for slo- 2 were 5 '-GAAGGG AAAAGTTGGAAATTTGG (forward) and $5^{\prime}$-AGTGATCATTCGAAG TCTTGGGA (reverse). Primers for act-1 were $5^{\prime}$-GCCCAATCCAAG AGAGGTATCC (forward) and $5^{\prime}$-TGAGGAGGACTGGGTGCTCT (reverse).

RNA immunopurification. The Prab-3::hrpu-2::GFP transgene was integrated into the genome via $\gamma$-irradiation, and the integrant was backcrossed with wild type five times. RNA immunopurification (RIP) assays were performed with the integrated strain using the Magna RIP RNABinding Protein Immunoprecipitation Kit (Millipore) according to manufacturer instructions. Briefly, mixed-stage worms were homogenized and lysed in RIP lysis buffer, and an equal amount of the lysate was incubated with either a mouse anti-GFP antibody (clone N86/38, NeuroMab, University of California, Davis, Davis, CA) or a control IgG (Millipore) bound to protein $\mathrm{A} / \mathrm{G}$ magnetic beads. After washing off unbound materials, the magnetic beads were treated with protease $\mathrm{K}$ to digest the protein and RNA was extracted subsequently. qRT-PCR was performed as described 
A
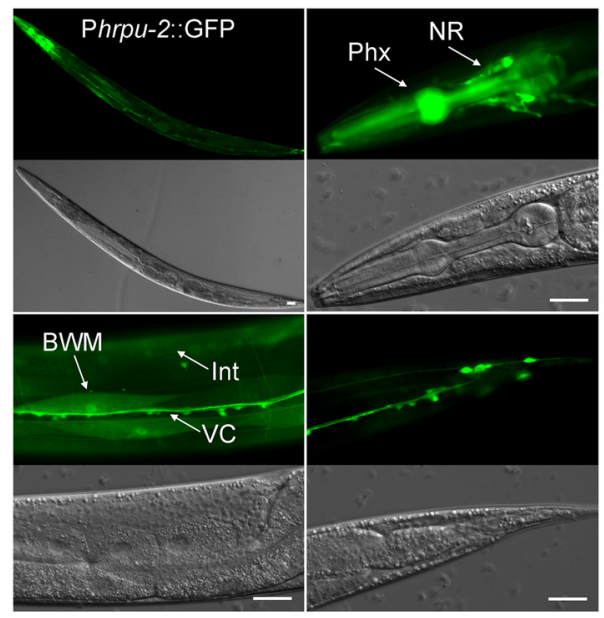

B
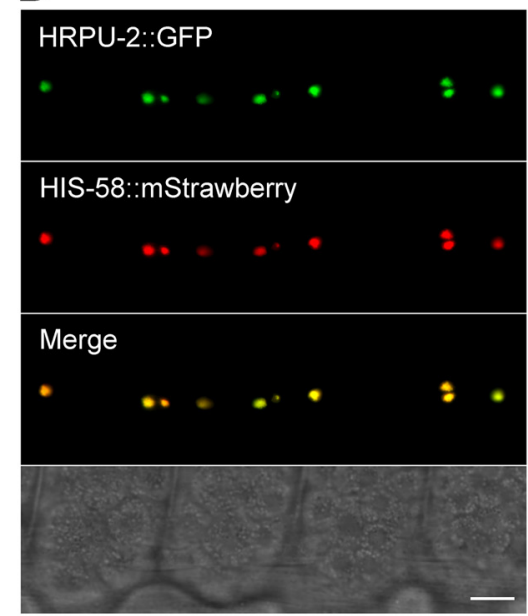

C
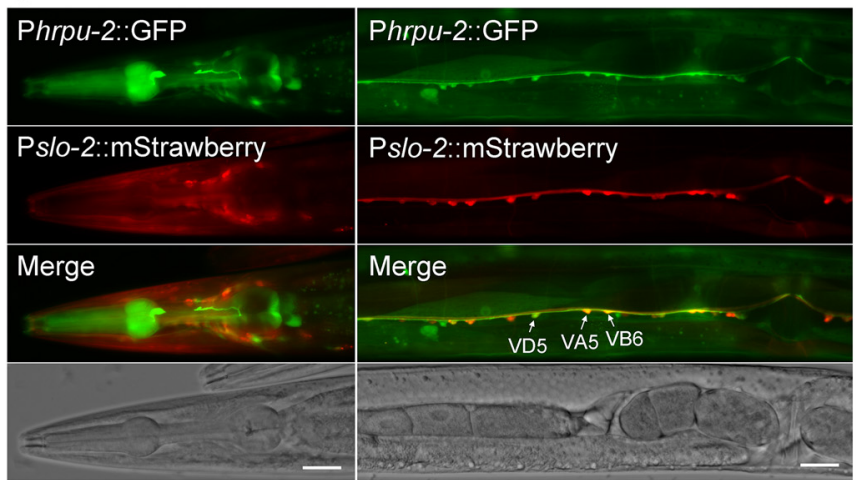

Figure 3. Expression and subcellular localization patterns of HRPU-2.A, Expression of a GFP reporter under the control of $h r p u-2$ promoter in wild-type worms shows that $h r p u-2$ is expressed in many neurons in the nerve ring (NR) and along the ventral nerve cord (VC), pharynx (Phx), intestine (Int), body-wall muscles (BWM), and other unidentified cells. B, HRPU-2 is localized in the nucleus of neurons. Shown are fluorescence images of the ventral nerve cord of a transgenic worm coexpressing GFP-tagged HRPU-2 and mStrawberry-tagged HIS-58 (nucleus marker). C, hrpu-2 is coexpressed with slo-2 in body-wall muscle cells and many neurons including VA5, VD5, and VB6 motor neurons in the ventral nerve cord. Scale bar, $20 \mu \mathrm{m}$.

earlier. Primers for $s$ lo- 1 were 5 '-TCTGTTCGGTTTGGCCATGT (forward) and $5^{\prime}$-CACGTCATCACGGTCCTCGT (reverse). Primers for shk-1 were 5'-TTTCTTCGCGGACACAAGC (forward) and 5'-ACCAGAGCAATT GCCATGAAG (reverse).

Data analyses for electrophysiology. Amplitudes of whole-cell currents in response to voltage steps were determined from the mean current during the last $100 \mathrm{~ms}$ of the $1200 \mathrm{~ms}$ voltage pulses using Clampfit software. The duration and charge transfer of PSC bursts were quantified with Clampfit software (version 10, Molecular Devices), as previously described (Liu et al., 2013). The frequency of PSC bursts was manually counted. Statistical comparisons were performed with Origin Pro 2017 (OriginLab) using either ANOVA or unpaired $t$ test, as specified in figure legends. $p<0.05$ is considered to be statistically significant. The sample size $(n)$ equals the number of cells or membrane patches analyzed. All values are shown as the mean $\pm \mathrm{SE}$, and data graphing was performed with Origin Pro 2017.

\section{Results}

Mutating SLO-2 S6 creates a hyperactive channel

To identify proteins important to SLO-2 function in vivo using a forward genetic approach, it is necessary to create a strain expressing a hyperactive SLO-2 with an obvious behavioral phenotype. Because mutating two amino acid residues (glutamine 276 and tyrosine 279) in the S6 membrane-spanning domain of rat Slo2.1/ Slick to glutamate (Slick-EE) causes a large increase in singlechannel conductance (Chen et al., 2009), we tested whether similar changes may enhance SLO-2 channel function. While the S6 of the mutated Slo2.1 contains the amino acid sequence ELAEL, corresponding residues of wild-type SLO-2 are ELGQT (Fig. 1A). We therefore mutated GQT to AEL in SLO-2 and tested whether the mutation alters SLO-2 function in body-wall muscle cells. The mutated SLO-2 and wild-type SLO-2 were independently expressed in slo2(nf101), a putative null resulting from a deletion (Wei et al., 2002), using a cloned slo-1 promoter (Wang et al., 2001; Chen et al., 2010b), which is more effective in driving GFP reporter expression in neurons and muscle cells than a cloned slo-2 promoter (Lim et al., 1999; Yuan et al., 2000). The mutation caused several changes in SLO-2 single-channel properties, including a larger conductance (116.9 \pm 0.9 vs $110.2 \pm 1.0 \mathrm{pS}$; $p<0.001)$, a higher open probability at hyperpolarizing voltages $(0.54 \pm 0.03$ vs $0.12 \pm 0.03$ at $-50 \mathrm{mV} ; p<0.001)$, and a loss of voltage dependence (Fig. $1 B$ ). In addition, the mutation caused faster activation of whole-cell currents, a shift of the conductance-voltage relationship to a more hyperpolarized voltage range (Fig. $1 C$ ), and a more hyperpolarized resting membrane potential $(-71.6 \pm 2.7 \mathrm{vs}-37.3 \pm 4.0 \mathrm{mV}$; $p<0.001$; Fig. 1D). These observations suggest that the mutated SLO-2 is a hyperactive channel. We henceforth refer to it as gainof-function ( $g$ ) SLO-2 or SLO-2( $g$ ).

\section{hrpu-2 mutants suppress slo-2(gf) lethargy}

Worms expressing the slo-2(gf) transgene displayed a sluggish phenotype. We subsequently integrated the transgene into the genome, and performed a forward genetic screen for suppressors of the sluggish phenotype of the strain (Fig. 2A). Seventeen suppressors were isolated from screening 30,000 haploid genomes. Analyses of whole-genome sequencing data indicated that 9 of the 17 isolated mutants carry either nonsense or mis-sense mutations in the gene hrpu-2, which encodes a homolog of mammalian hnRNP $U$ with two predicted translational products: HRPU-2a and HRPU-2b (www.wormbase. org). These two isoforms differ in only the presence or absence of two amino acid residues. Although HRPU-2a and HRPU-2b are only $16 \%$ identical to human and mouse hnRNP U, they contain key structural domains found in the mammalian homologs, including an acidic residue-rich domain in the $\mathrm{N}$ terminal, and a nuclear localization signal (NLS) and an RGG box in the C terminal (Fig. $2 B, C$ ). Seven of the nine identified HRPU-2 mutations are in the acidic residue-rich $\mathrm{N}$ terminal, while the remaining two are in the middle of HRPU-2 (Fig. $2 B, C$ ). All the mutations appear to be recessive in nature because heterozygous hrpu-2 mutants with one wild-type allele cannot suppress the SLO-2(gf) lethargy and because phenotypes of homozygous hrpu-2 mutants can be fully rescued by expressing wild-type HRPU-2 (shown later). Several of the mutants, such as $z w 65$ and $z w 75$, are likely nulls because they carry nonsense mutations near the $\mathrm{N}$ terminus of HRPU-2. 


\section{SLO-2 $(g f)$ is inhibited in $h r p u-2$} mutants

The suppression of the slo-2(gf) lethargic phenotype by $h r p u-2$ mutants could result from either a dysfunction of SLO-2 or a SLO-2-independent mechanism. In $C$. elegans, cholinergic motor neurons control body-wall muscle cells by producing bursts of PSCs (Liu et al., 2013), and SLO-2 plays important roles in motor neuron function (Liu et al., 2014). To determine whether $h r p u$-2(lf) suppresses the lethargy through SLO-2, we recorded voltage-activated whole-cell outward currents from a representative cholinergic motor neuron (VA5) and postsynaptic currents from body-wall muscle cells, and compared them among wild type, slo-2(gf), slo-2(gf); hrpu-2(zw65), and slo-2(gf); hrpu-2(zw65) with $h r p u-2$ rescued in neurons. In wholecell current recordings, the slo-2(gf) strain displayed significantly larger outward currents than wild type and apparent voltage-dependent inactivation that was not observed in wild type (Fig. 2D). In postsynaptic current recordings from muscle cells, the slo-2(gf) strain showed greatly decreased frequency and strength of PSC bursts (Fig. 2E). These electrophysiological phenotypes of slo-2(gf) were not observed in the slo-2(gf); $h r p u-$ $2(z w 65)$ strain but restored when wildtype $h r p u-2$ was expressed in neurons of the strain (Fig. 2D,E), suggesting that hrpu-2 mutations suppressed the sluggish phenotype through inhibiting SLO-2(gf). The behavioral phenotype of slo-2(gf) appears to be mainly due to SLO-2 hyperactivity in neurons as it was fully reinstated in the slo2(gf); hrpu-2(zw65) strain when wild-type hrpu-2 was expressed as a transgene in neurons (Fig. 2A).

HRPU-2 is widely expressed and localized in the nucleus The electrophysiological results described above suggest that $h r p u-2$ is expressed in motor neurons. To confirm this and identify any other cells expressing $h r p u-2$, we fused a $3.1 \mathrm{~kb}$ genomic DNA fragment upstream of the $h r p u-2$ translation initiation site to GFP and expressed this transcriptional fusion (Phrpu-2::GFP) in wild-type worms. In transgenic worms, GFP signal was observed in a variety of cell types, including motor neurons and many other neurons, body-wall muscle cells, pharyngeal muscle cells, and intestinal cells (Fig. 3A). To determine the subcellular localization pattern of HRPU-2, we tagged HRPU-2a by GFP at its $\mathrm{C}$ terminus and expressed the fusion protein in neurons under the control of the pan-neuronal rab-3 promoter (Prab-3). The fusion protein is expected to recapitulate the subcellular localization pattern of wild-type HRPU-2 because, as described below, it fully rescues deficient SLO-2 currents in VA5 of hrpu-2(zw65). In motor neurons expressing the fusion protein, GFP signal colocalized with mStrawberry-tagged HIS-58, which is a nuclear marker (Fig. $3 B$ ), suggesting that HRPU-2 is localized in the nucleus.

To determine whether HRPU-2 is coexpressed with SLO-2, we created a transgenic strain expressing Pslo-2::mStrawberry and crossed this transgene into the Phrpu-2::GFP strain. In the resultant strain, both transgenes are expressed in body-wall muscle cells and many neurons, including the VA5 and VD5 motor neurons used for electrophysiological recordings, although their expression patterns differ in some tissues such as pharyngeal muscles (Fig. $3 C$ ). The coexpression of HRPU-2 and SLO-2 in many cells is in agreement with the behavioral and electrophysiological results, suggesting that HRPU-2 is important to SLO-2 function.

Since HRPU-2 is highly expressed in many neurons (Fig. 3A), we asked whether it plays an important role in neural development. To this end, we expressed GFP and monomeric RFP (mRFP) independently under the control of unc-17 (vesicle acetylcholine transporter) and unc-47 (vesicular GABA transporter) promoters, respectively, and compared the gross morphology of the labeled cholinergic and GABAergic motor neurons between wild type and $h r p u-$ 2(zw65). Gross morphology, including the number and locations of motor neurons, was indistinguishable between wild type and the mutant (Fig. 4A, B). These observations suggest that HRPU-2 does not play an obvious role in neural development.

\section{HRPU-2 regulates synaptic transmission through SLO-2}

We next determined whether the function of wild-type SLO-2 also depends on HRPU-2 by comparing whole-cell outward currents 

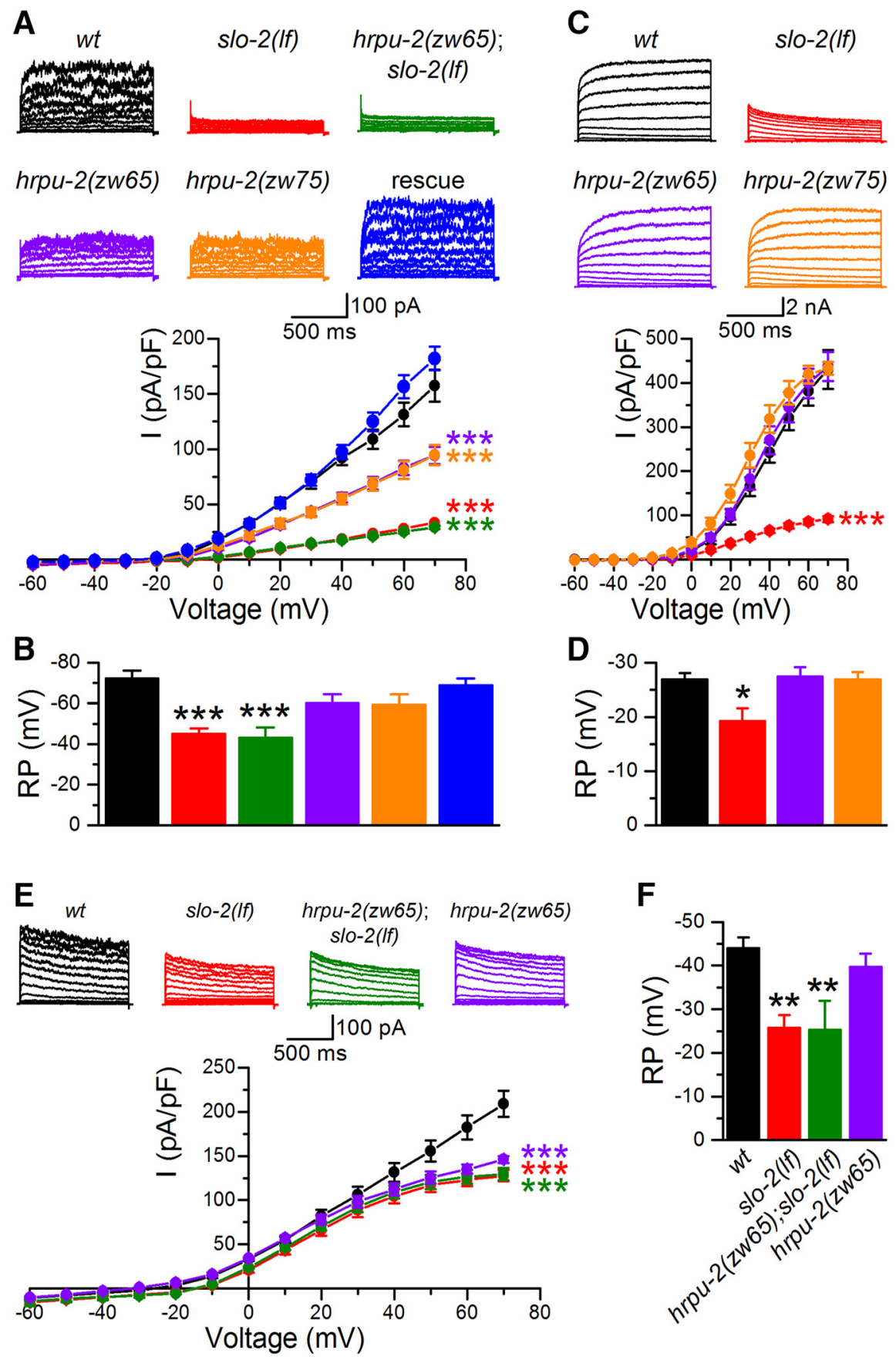

Figure 5. HRPU-2 regulates whole-cell currents of VA5 and VD5 motor neurons through SLO-2. $\boldsymbol{A}$, Effects of slo-2(If) and hrpu-2(If) mutants on VA5 whole-cell currents. Shown are sample current traces and current-voltage relationships. The sample sizes were 8 wild type (wt), 9 slo-2(If), 10 hrpu-2(zw65);slo-2(If), 7 hrpu-2(zw65), 6 hrpu-2(zw75), and 8 hrpu-2(zw65) expressing GFP-tagged wild type HRPU-2 in neurons (rescue). $\boldsymbol{B}$, Comparison of the resting membrane potential of VA5 among the different strains. Sample sizes were identical to those in $\boldsymbol{A}$. C, hrpu-2(If) mutants have normal muscle whole-cell currents. $\boldsymbol{D}$, hrpu-2(If) mutants have normal resting membrane potential in muscle cells. $\boldsymbol{E}$, Effects of s/o-2(If) and $h r p u-2$ (If) mutants on VD5 whole-cell currents. Shown are sample current traces and current-voltage relationships. The sample sizes were $10 \mathrm{wt}, 7 \mathrm{slo}-2$ (If), $7 \mathrm{hrpu}$ 2(zw65);slo-2(If), and 9 hrpu-2(zw65). F, Comparison of the resting membrane potential of VD5 among the four groups. Sample sizes were 11 wt, 7 slo-2(lf), 7 hrpu-2(zw65);slo-2(If), and 8 hrpu-2(zw65). Pipette solution I and bath solution I were used in all experiments. The asterisks indicate a significant difference compared with wt $\left({ }^{*} p<0.05 ;{ }^{* *} p<0.01 ;{ }^{* * *} p<0.001\right.$. Tw0-way $(\boldsymbol{A}, \boldsymbol{C}, \boldsymbol{E})$ or one-way $(\boldsymbol{B}, \boldsymbol{D}, \boldsymbol{f})$ ANOVA with Tukey's post hoc tests).

and the resting membrane potential of VA5 among wild-type, slo-2(lf), hrpu-2 mutants (zw65 and zw75), slo-2(lf);hrpu-2(zw65) double mutants, and hrpu-2(zw65) with hrpu-2 recued in neurons. Delayed outward currents were greatly decreased in slo2(lf) compared with wild type (Fig. 5A), which is consistent with previous reports (Yuan et al., 2003; Liu et al., 2011, 2014). hrpu-2(lf) mutants also showed a large (approximately one-third) decrease in the delayed outward currents, and this effect was not additive with that of slo-2(lf) (Fig. 5A), suggesting that HRPU-2 regulates SLO-2. The deficiency of motor neuron delayed outward currents in $h r p u-2(l f)$ could be rescued by the expression of GFP-tagged HRPU-2a in the same cells (Fig. 5A), suggesting that HRPU-2 acts cell autonomously to regulate SLO-2 function and that the GFP-tagged HRPU-2 is a functional protein. The resting membrane potential of VA5 became less hyperpolarized in slo-2(lf) compared with wild type (Fig. 5B). However, the resting membrane potential of VA5 in both hrpu-2(lf) mutants was not significantly different from that in wild type (Fig. 5B), suggesting that either the remaining SLO-2 activity is sufficient to maintain the normal resting membrane potential or hrpu-2(lf) may alter the resting membrane potential in the opposite direction through affecting the expression of an unidentified protein. We also compared whole-cell currents and the resting membrane potential of muscle cells among wild type, slo-2(lf), and the two hrpu-2(lf) mutants. Unlike slo-2(lf), both hrpu-2(lf) mutants had normal muscle whole-cell currents and resting membrane potential (Fig. $5 C, D)$, suggesting that HRPU-2 does not regulate SLO-2 in muscle cells.

To determine whether HRPU-2 regulates SLO-2 in other types of neurons, we recorded whole-cell outward currents and the resting membrane potential from a representative GABA motor neuron (VD5) in wild type, slo-2(lf), hrpu-2(zw65), and slo2(lf); hrpu-2(zw65) double mutant. Consistent with our previous report (Liu et al., 2014), the whole-cell currents of VD5 were reduced by approximately one-third in slo2(lf) mutant compared with wild type (Fig. $5 E)$. The whole-cell currents in VD5 of hrpu-2(lf) mutant were also significantly reduced, and this effect was not additive with that of slo-2(lf) (Fig. 5E). In addition, similar to the results obtained with VA5, the resting membrane potential of VD5 became significantly less hyperpolarized in slo-2(lf) but not hrpu-2(lf) compared with wild type (Fig. 5f). These observations suggest that HRPU-2 also regulates SLO-2 in GABA motor neurons.

SLO-2 channels constitute an important regulator of synaptic transmission in C. elegans. At the neuromuscular junction, they act to reduce the duration and charge transfer rate of PSC bursts (Liu et al., 2014). To determine whether HRPU-2 is required for this function of SLO-2, we compared PSC bursts recorded from body-wall muscle cells between wild type and different mutant strains. Similar to 
slo-2(lf) mutant, the hrpu-2(lf) mutants showed increased duration and charge transfer rate of PSC bursts without a change in burst frequency, and these mutant phenotypes were not additive with those of slo-2(lf) and could be rescued by the expression of wild-type HRPU-2 in neurons (Fig. 6A,B), suggesting that HRPU-2 regulates synaptic transmission through presynaptic SLO-2.

\section{HRPU-2 regulates SLO-2 expression in neurons}

The most common function known for hnRNPs is to regulate gene expression. Therefore, the reduced SLO-2 currents in VA5 and the altered PSC burst properties at the neuromuscular junction in $h r p u-$ 2(lf) mutants could be due to a decrease in SLO-2 expression. To examine this possibility, we first generated a transgenic strain expressing SLO-2::GFP under the control of Prab-3 with wild-type worms and then crossed the extrachromosomal array into $h r p u-2(z w 65)$ and $h r p u-2(z w 75)$ to maintain the transgene dosage. SLO-2:: GFP, in which GFP was fused to the C terminus of SLO-2, is a functional protein because it can completely rescue the deficiency of neuronal whole-cell currents in slo-2(lf) (Liu et al., 2014). GFP signal was reduced by $>50 \%$ in the two mutant strains compared with wild type (Fig. 7A), suggesting that HRPU-2 plays an important role in SLO-2 protein expression. In contrast, the expression of SLO-2::GFP in body-wall muscle cells under the control of the muscle-specific myo-3 promoter was comparable between wild type and the $h r p u$-2(lf) mutants (Fig. $7 B$ ), which is consistent with the electrophysiological results (Fig. 5). To confirm the effect of hrpu-2(lf) on SLO-2::GFP expression in neurons, we performed Western blot analysis with the strains expressing Prab$3:: S L O-2:: G F P$ using an anti-GFP antibody. Consistently, the SLO-2::GFP protein level was also significantly reduced in hrpu-2(lf) mutants compared with wild type (Fig. $7 C$ ). It appears that HRPU-2 does not regulate protein expression indiscriminately because neuronal expression of GFP-tagged SLO-1 and SHK-1, two important potassium channels in neurons (Wang et al., 2001; Liu et al., 2014), was not compromised by hrpu-2(lf) (Fig. 7D).

What is the cause for decreased SLO-2 protein level in hrpu2(lf) mutants? Because hnRNP U plays roles in facilitating gene transcription and maintaining mRNA stability, the decreased SLO-2 protein level in the mutants might result from decreased slo-2 mRNA. To address this possibility, we compared slo-2 mRNA level between wild type and the $h r p u-2(l f)$ mutants (zw65 and zw75) by
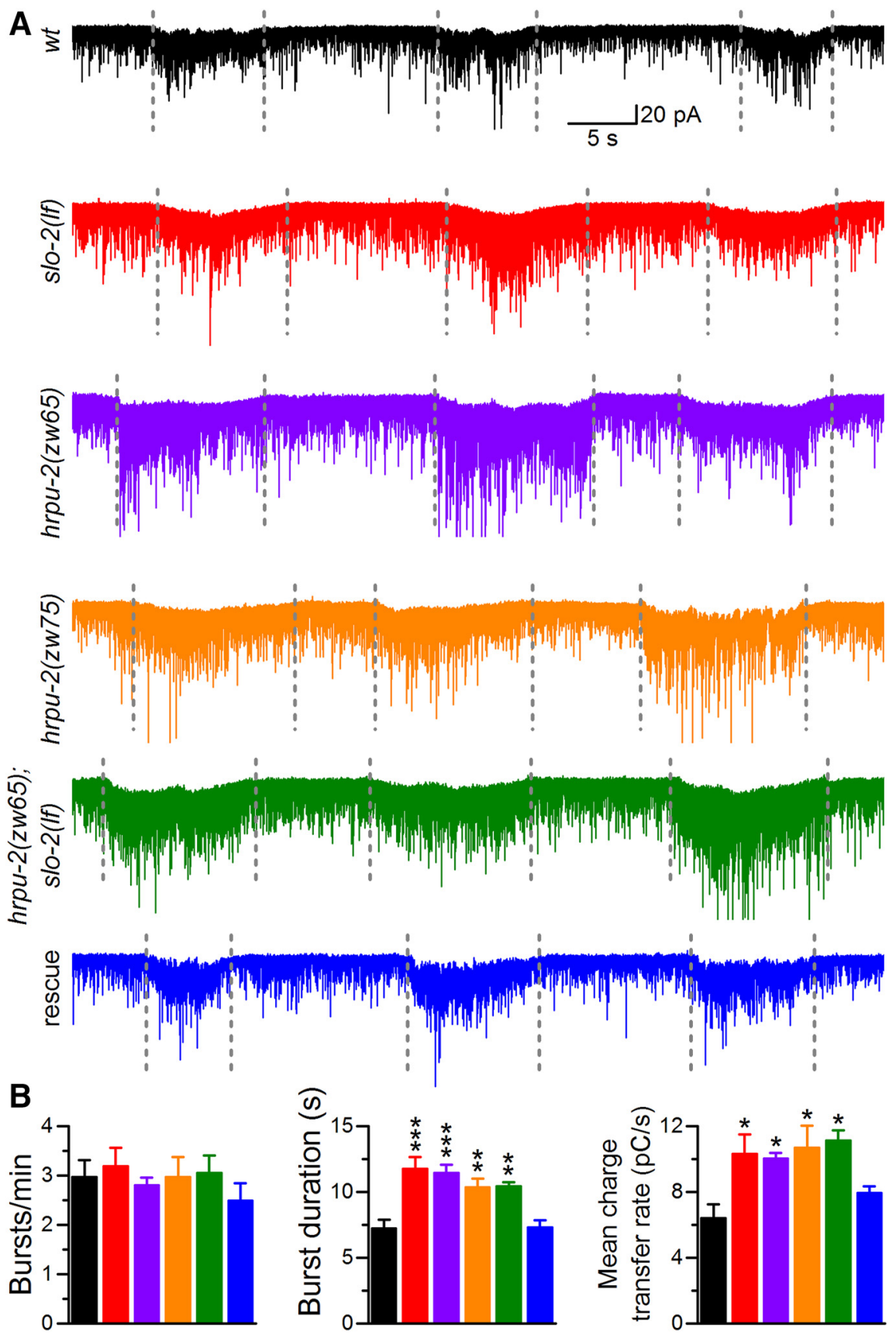

Figure 6. HRPU-2 regulates PSC bursts through presynaptic SLO-2.A, Representative traces of spontaneous PSCs recorded from muscle cells of wild type (wt) and mutant strains. The vertical dotted lines mark PSC bursts, which are defined as an apparent increase in PSC frequency accompanied by a baseline drop lasting $>3 \mathrm{~s}$. $\boldsymbol{B}$, Comparison of the frequency, duration, and mean charge transfer rate of PSC bursts among the different groups. The sample sizes were $8 \mathrm{wt}, 7$ slo-2(If), $8 \mathrm{hrpu}-2(\mathrm{zw} 65), 8 \mathrm{hrpu}$ 2(zw75), 7 hrpu-2(zw65);slo-2(If), and 8 hrpu-2(zw65) expressing GFP-tagged wild-type HRPU-2 in neurons (rescue). Pipette solution II and bath solution I were used. The asterisks indicate a significant difference compared with $w t\left({ }^{*} p<0.05 ;{ }^{* *} p<0.01\right.$; ${ }^{* * *} p<0.001$, one-way ANOVA with Tukey's post hoc tests).

quantitative RT-PCR. We observed an increase $(\sim 10 \%)$ rather than a decrease of slo-2 mRNA in the mutants compared with wild type (Fig. 7E). Thus, the reduction of SLO-2 protein in the hrpu-2 mutants is not due to decreased slo-2 mRNA.

We next determined whether HRPU-2 binds to slo-2 mRNA by performing an RIP assay. This assay requires the use of an antibody for immunoprecipitating HRPU-2. Because HRPU-2 antibody was unavailable and tagging HRPU-2 with GFP at its C terminus did not alter its function (Fig. 5), we used a GFP anti- 

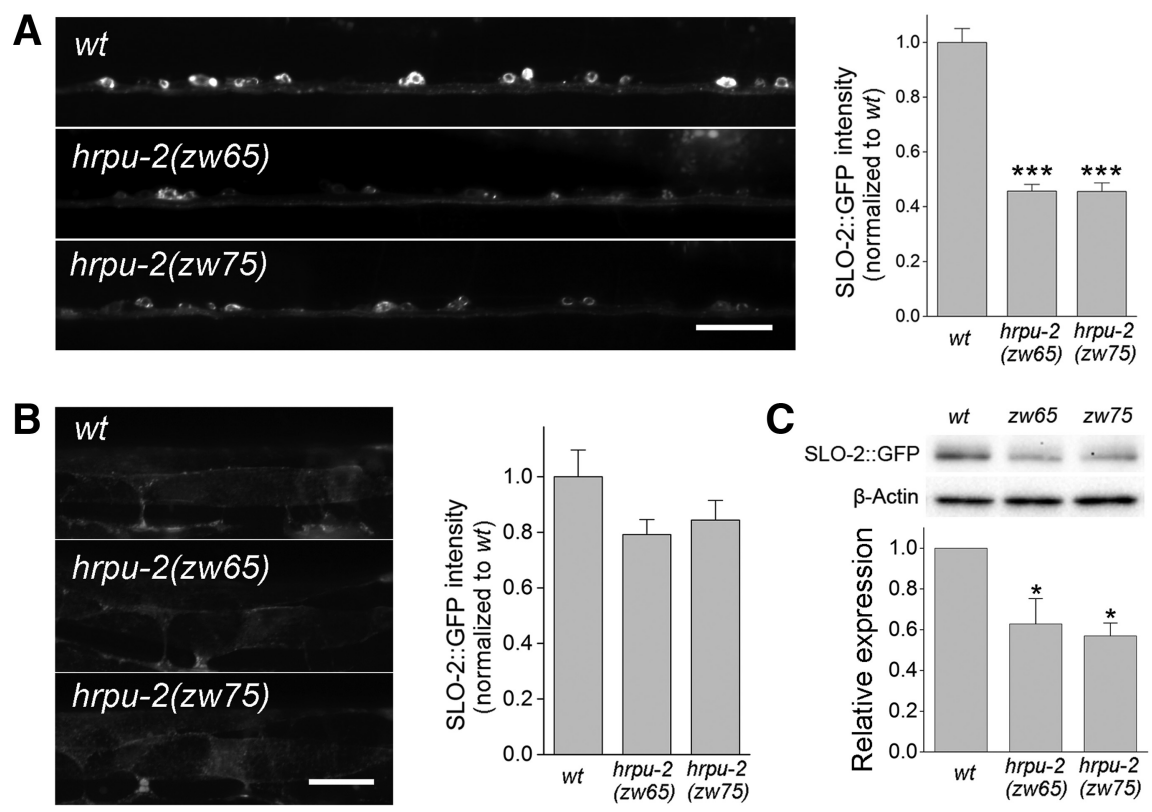

D
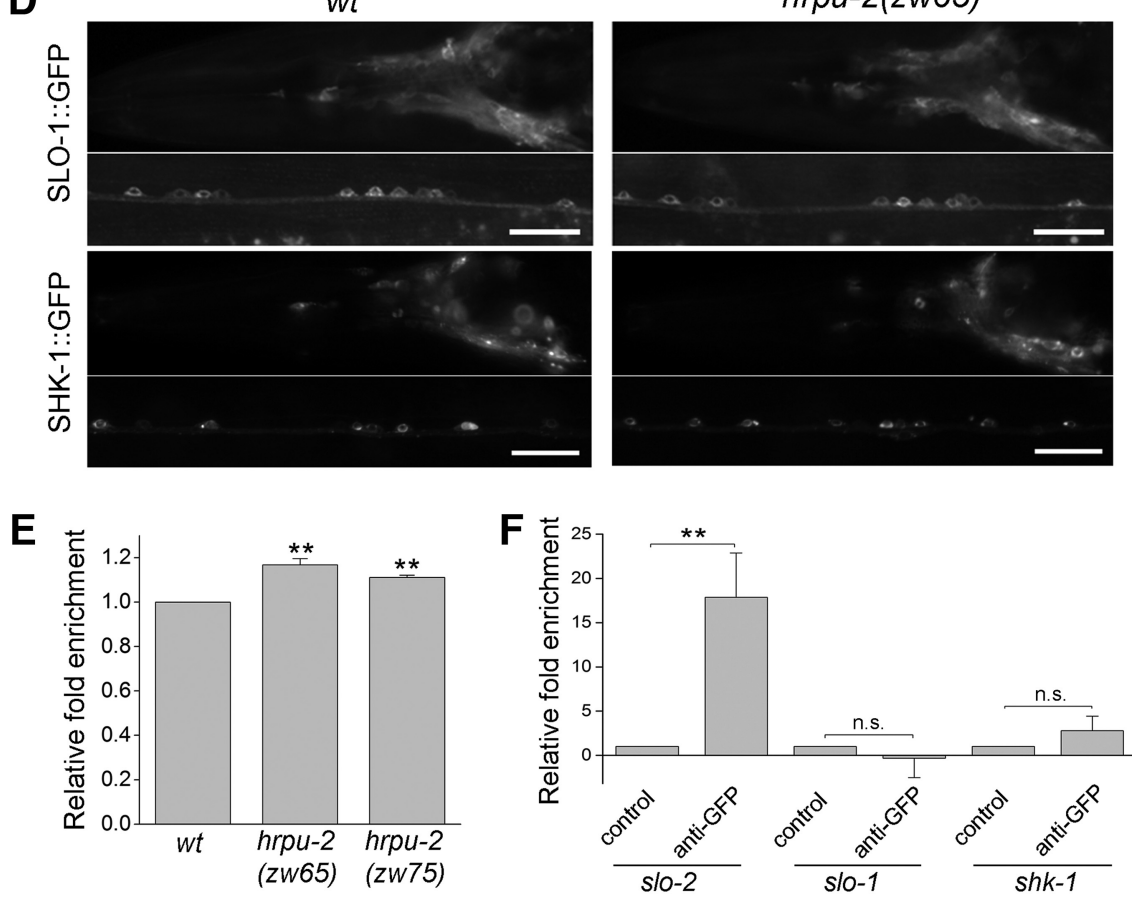

Figure 7. HRPU-2 regulates SLO-2 expression post-transcriptionally. $A$, Expression of SLO-2::GFP in motor neurons under the control of rab-3 promoter is reduced in hrpu-2(If) mutants. Left, Representative images of posterior segments of the ventral nerve cord from wild type (wt) and hrpu-2(If) mutants. Right, Comparison of SL0-2::GFP signal normalized to wt. The sample sizes were $18 w t, 21 \mathrm{hrpu}-2(z w 65)$, and $17 \mathrm{hrpu}-2(z w 75)$. B , Expression of SL0-2::GFP in body-wall muscle cells under the control of myo-3 promoter is comparable between wt and hrpu-2(If) mutants. Left, Representative images from wt and hrpu-2(If) mutants. Right, Comparison of SLO-2::GFP signal normalized to wt. The sample sizes were 22 wt, 20 hrpu-2(zw65), and 23 hrpu-2(zw75). C, SLO2::GFP protein level in neurons is reduced in hrpu-2 mutants in Western blot analysis. SL0-2::GFP signal (quantified by densitometry using the ImageJ software) was first normalized with $\beta$-actin and then normalized to wt for comparison. Shown are the mean \pm SEM from three independent experiments. D, Expression of SL0 $1::$ GFP and SHK-1::GFP is simila between wt and hrpu-2(zw65). $\boldsymbol{E}$, slo-2 mRNA level is increased in hrpu-2(If) mutants. Shown are the mean \pm SEM from three independent experiments. $\boldsymbol{F}$, slo-2 mRNA but not slo- 1 or shk-1 mRNA is enriched in immunoprecipitates of HRPU2::GFP. RNA immunoprecipitation assays were performed with a mouse GFP antibody and control mouse IgG. Shown are mean \pm SEM values from three independent experiments. The asterisks indicate a significant difference compared with either wt or control (n.S., $p>0.05 ;{ }^{*} p<0.05 ;{ }^{* *} p<0.01 ;{ }^{* * *} p<0.001$. One-way ANOVA with Tukey's post hoc tests). Scale bars: $\boldsymbol{A}, \boldsymbol{B}$, and $\boldsymbol{D}, 20 \mu \mathrm{m}$. body to immunoprecipitate mRNAs from the HRPU-2::GFP strain and compared the amount of immunoprecipitated slo-2 mRNA with that immunoprecipitated with control serum by quantitative RT-PCR. slo- 2 mRNA was enriched by $>17$-fold in immunoprecipitates with the GFP antibody compared with the control (Fig. 7f), suggesting that HRPU-2 binds to slo-2 mRNA directly. In contrast, HRPU-2 does not bind to either slo-1 mRNA or shk-1 mRNA (Fig. $7 f$ ).

\section{Discussion}

The present study shows that HRPU-2 plays a critical role in SLO-2 function in vivo by regulating SLO-2 protein expression. This conclusion is supported by several lines of evidence, including the isolation of multiple hrpu-2(lf) mutants as suppressors of slo-2(gf) sluggish phenotype, great decreases of SLO-2 currents, and SLO-2-dependent functions in neurons of $h r p u-2$ (lf) mutants, and a large decrease in the expression of GFP-tagged SLO-2 in hrpu-2(lf) mutants.

HRPU-2 is a homolog of mammalian hnRNP U. Mammalian hnRNPs can regulate protein expression through acting at various steps of protein synthesis, including gene transcription, mRNA maturation, translocation of mRNA from the nucleus to the cytosol, and translation of mRNA into proteins (Han et al., 2010; Geuens et al., 2016). Our results show that a deficiency of HRPU-2 causes a great reduction of SLO-2 protein without a decrease of slo-2 mRNA. Because our assay for the effects of hrpu-2(lf) on SLO-2 expression was performed with a GFP-tagged SLO-2, in which SLO-2 was encoded by a slo- 2 cDNA, the reduced SLO-2 expression did not result from a defect in slo-2 mRNA splicing. Thus, HRPU-2 likely regulates SLO-2 expression through an effect on either mRNA nucleus to cytosol translocation or mRNA translation.

Both HRPU-2 and FMRP are RNAbinding proteins that are important to the function of Slo2 channels. They have in common an RGG box that mediates RNA binding. However, they differ in mechanisms regulating Slo2 channels. While FMRP binds to Slo2.2 protein to regulate channel activity, HRPU-2 binds to slo-2 mRNA to regulate SLO-2 protein expression. In addition, they differ in their roles with respect to Slo1, another member of the Slo potassium channel family. While a deficiency of FMRP causes reduced Slo1 activity (Deng et al., 2013; Deng and Klyachko, 2016), hrpu-2(lf) mutants show neither altered SLO-1::GFP expression 
nor a head-bending phenotype characteristic of slo-1(lf) mutants (Kim et al., 2009; Chen et al., 2010a). The fact that FMRP and HRPU-2 are among the earliest identified Slo2 regulators suggests that RNA-binding proteins might play critical roles in regulating the function of this family of potassium channels.

Although $h r p u-2(l f)$ greatly compromised SLO-2 function in vivo, it showed few other effects in our analyses. For example, hrpu-2(lf) mutants are similar to wild type in the expression of GFP-tagged SLO-1 and SHK-1, gross neural morphology, and locomotion speed. In contrast, mammalian hnRNP U plays crucial roles in development. For example, a hypomorphic mutation of the gene causes early embryonic lethality (Roshon and Ruley, 2005). Since the C. elegans genome contains another gene encoding an hnRNP U-like protein ( $h r p u-1$; www.wormbase.org), functional redundancy between these two genes might account for the apparently normal development and locomotion of $h r p u-$ 2(lf) worms. In addition, our observation that a deficiency of HRPU-2 compromises SLO-2 expression in neurons but not muscle cells also suggests that there likely exists functional redundancy between HRPU-2 and other regulators. Although HRPU-2 does not regulate muscle SLO-2, $h r p u$-2 (lf) fully suppressed the slo-2(gf) sluggish phenotype (Fig. $2 A)$. This may seem to be intriguing given that SLO-2 $(g f)$ has significant effects on whole-cell currents and the resting membrane potential in muscle cells (Fig. $1 C, D)$. The apparent discrepancy is probably because the increased neuromuscular transmission from motor neurons in hrpu-2(lf) (Fig. 6) can counteract the inhibitory effect of muscle SLO-2 $(g f)$ on locomotion.

hnRNPs have been implicated in neuronal activity-dependent regulation of gene expression. For example, membrane depolarization can induce high-affinity interactions between hnRNP A2 and RNAs with a specific targeting motif to facilitate RNA delivery to dendritic sites of protein synthesis (Muslimov et al., 2014) and can regulate alternative splicing of Slo1 potassium channel and neurexin $2 \alpha$ through hnRNP L (Liu et al., 2012; Rozic et al., 2013). Since the expression/function of hnRNPs are subject to changes in neuronal activities (Liu et al., 2012; Kolisnyk et al., 2016), HRPU-2 might contribute to activity-dependent neuronal plasticity by regulating SLO-2 expression.

Epileptic seizures and intellectual disability are disorders afflicting millions of people worldwide and resulting from many different causes. Slo2 channels play predominant roles in conducting outward currents in many neurons. Mutations of Slo2.2/ Slack are strongly linked with epilepsies and intellectual disability (Barcia et al., 2012; Heron et al., 2012; Helbig and Lowenstein, 2013; Kaczmarek, 2013; Evely et al., 2017). Increasing evidence indicates that mutations of hnRNA $U$ are also associated with such disorders (Caliebe et al., 2010; Ballif et al., 2012; Nagamani et al., 2012; Selmer et al., 2012; Thierry et al., 2012). The similarities in clinical presentations among patients with mutations of Slo2 and hnRNP U and our finding that HRPU-2 regulates SLO-2 expression raise the interesting possibility that the expression of Slo2 is also regulated by hnRNP $\mathrm{U}$ in mammals.

\section{References}

Abraham LS, Oh HJ, Sancar F, Richmond JE, Kim H (2010) An alphacatulin homologue controls neuromuscular function through localization of the dystrophin complex and BK channels in Caenorhabditis elegans. PLoS Genet 6:e1001077. CrossRef Medline

Allen AS, Berkovic SF, Cossette P, Delanty N, Dlugos D, Eichler EE, Epstein MP, Glauser T, Goldstein DB, Han Y, Heinzen EL, Hitomi Y, Howell KB, Johnson MR, Kuzniecky R, Lowenstein DH, Lu YF, Madou MR, Marson AG, Mefford HC, et al (2013) De novo mutations in epileptic encephalopathies. Nature 501:217-221. CrossRef Medline
Ballif BC, Rosenfeld JA, Traylor R, Theisen A, Bader PI, Ladda RL, Sell SL, Steinraths M, Surti U, McGuire M, Williams S, Farrell SA, Filiano J, Schnur RE, Coffey LB, Tervo RC, Stroud T, Marble M, Netzloff M, Hanson $\mathrm{K}$, et al (2012) High-resolution array CGH defines critical regions and candidate genes for microcephaly, abnormalities of the corpus callosum, and seizure phenotypes in patients with microdeletions of 1q43q44. Hum Genet 131:145-156. CrossRef Medline

Barcia G, Fleming MR, Deligniere A, Gazula VR, Brown MR, Langouet M, Chen H, Kronengold J, Abhyankar A, Cilio R, Nitschke P, Kaminska A, Boddaert N, Casanova JL, Desguerre I, Munnich A, Dulac O, Kaczmarek LK, Colleaux L, Nabbout R. De novo gain-of-function (2012) KCNT1 channel mutations cause malignant migrating partial seizures of infancy. Nat Genet 44:1255-1259. CrossRef Medline

Bausch AE, Dieter R, Nann Y, Hausmann M, Meyerdierks N, Kaczmarek LK, Ruth P, Lukowski R (2015) The sodium-activated potassium channel Slack is required for optimal cognitive flexibility in mice. Learn Mem 22:323-335. CrossRef Medline

Bhattacharjee A, Gan L, Kaczmarek LK (2002) Localization of the Slack potassium channel in the rat central nervous system. J Comp Neurol 454: 241-254. CrossRef Medline

Bhattacharjee A, von Hehn CA, Mei X, Kaczmarek LK (2005) Localization of the $\mathrm{Na}^{+}$-activated $\mathrm{K}^{+}$channel Slick in the rat central nervous system. J Comp Neurol 484:80-92. CrossRef Medline

Bramswig NC, Lüdecke HJ, Hamdan FF, Altmüller J, Beleggia F, Elcioglu NH, Freyer C, Gerkes EH, Demirkol YK, Knupp KG, Kuechler A, Li Y, Lowenstein DH, Michaud JL, Park K, Stegmann APA, Veenstra-Knol HE, Wieland T, Wollnik B, Engels H, et al (2017) Heterozygous HNRNPU variants cause early onset epilepsy and severe intellectual disability. Hum Genet 136:821-834. CrossRef Medline

Brown MR, Kronengold J, Gazula VR, Chen Y, Strumbos JG, Sigworth FJ, Navaratnam D, Kaczmarek LK (2010) Fragile X mental retardation protein controls gating of the sodium-activated potassium channel Slack. Nat Neurosci 13:819-821. CrossRef Medline

Budelli G, Hage TA, Wei A, Rojas P, Jong YJ, O’Malley K, Salkoff L (2009) $\mathrm{Na}^{+}$-activated $\mathrm{K}^{+}$channels express a large delayed outward current in neurons during normal physiology. Nat Neurosci 12:745-750. CrossRef Medline

Caliebe A, Kroes HY, van der Smagt JJ, Martin-Subero JI, Tönnies H, van 't Slot R, Nievelstein RA, Muhle H, Stephani U, Alfke K, Stefanova I, Hellenbroich Y, Gillessen-Kaesbach G, Hochstenbach R, Siebert R, Poot M (2010) Four patients with speech delay, seizures and variable corpus callosum thickness sharing a $0.440 \mathrm{Mb}$ deletion in region 1q44 containing the HNRPU gene. Eur J Med Genet 53:179-185. CrossRef Medline

Carvill GL, Heavin SB, Yendle SC, McMahon JM, O'Roak BJ, Cook J, Khan A, Dorschner MO, Weaver M, Calvert S, Malone S, Wallace G, Stanley T, Bye AM, Bleasel A, Howell KB, Kivity S, Mackay MT, Rodriguez-Casero V, Webster R, et al (2013) Targeted resequencing in epileptic encephalopathies identifies de novo mutations in CHD2 and SYNGAP1. Nat Genet 45:825-830. CrossRef Medline

Chen B, Liu P, Wang SJ, Ge Q, Zhan H, Mohler WA, Wang ZW (2010a) $\alpha$-Catulin CTN-1 is required for BK channel subcellular localization in C. elegans body-wall muscle cells. EMBO J 29:3184-3195. CrossRef Medline

Chen B, Ge Q, Xia XM, Liu P, Wang SJ, Zhan H, Eipper BA, Wang ZW (2010b) A novel auxiliary subunit critical to BK channel function in Caenorhabditis elegans. J Neurosci 30:16651-16661. CrossRef Medline

Chen B, Liu P, Zhan H, Wang ZW (2011) Dystrobrevin controls neurotransmitter release and muscle $\mathrm{Ca}^{2+}$ transients by localizing $\mathrm{BK}$ channels in Caenorhabditis elegans. J Neurosci 31:17338-17347. CrossRef Medline

Chen H, Kronengold J, Yan Y, Gazula VR, Brown MR, Ma L, Ferreira G, Yang Y, Bhattacharjee A, Sigworth FJ, Salkoff L, Kaczmarek LK (2009) The $\mathrm{N}$-terminal domain of Slack determines the formation and trafficking of Slick/Slack heteromeric sodium-activated potassium channels. J Neurosci 29:5654-5665. CrossRef Medline

Contreras GF, Neely A, Alvarez O, Gonzalez C, Latorre R (2012) Modulation of BK channel voltage gating by different auxiliary beta subunits. Proc Natl Acad Sci U S A 109:18991-18996. CrossRef Medline

de Kovel CG, Brilstra EH, van Kempen MJ, Van't Slot R, Nijman IJ, Afawi Z, De Jonghe P, Djémié T, Guerrini R, Hardies K, Helbig I, Hendrickx R, Kanaan M, Kramer U, Lehesjoki AE, Lemke JR, Marini C, Mei D, Møller RS, Pendziwiat M, et al (2016) Targeted sequencing of 351 candidate 
genes for epileptic encephalopathy in a large cohort of patients. Mol Genet Genomic Med 4:568-580. CrossRef Medline

Deng PY, Klyachko VA (2016) Genetic upregulation of BK channel activity normalizes multiple synaptic and circuit defects in a mouse model of fragile X syndrome. J Physiol 594:83-97. CrossRef Medline

Deng PY, Rotman Z, Blundon JA, Cho Y, Cui J, Cavalli V, Zakharenko SS, Klyachko VA (2013) FMRP regulates neurotransmitter release and synaptic information transmission by modulating action potential duration via BK channels. Neuron 77:696-711. CrossRef Medline

Depienne C, Nava C, Keren B, Heide S, Rastetter A, Passemard S, ChantotBastaraud S, Moutard ML, Agrawal PB, VanNoy G, Stoler JM, Amor DJ, Billette de Villemeur T, Doummar D, Alby C, Cormier-Daire V, Garel C, Marzin P, Scheidecker S, de Saint-Martin A, et al (2017) Genetic and phenotypic dissection of 1q43q44 microdeletion syndrome and neurodevelopmental phenotypes associated with mutations in ZBTB18 and HNRNPU. Hum Genet 136:463-479. CrossRef Medline

Evely KM, Pryce KD, Bhattacharjee A (2017) The Phe932Ile mutation in KCNT1 channels associated with severe epilepsy, delayed myelination and leukoencephalopathy produces a loss-of-function channel phenotype. Neuroscience 351:65-70. CrossRef Medline

Ferron L, Davies A, Page KM, Cox DJ, Leroy J, Waithe D, Butcher AJ, Sellaturay P, Bolsover S, Pratt WS, Moss FJ, Dolphin AC (2008) The stargazin-related protein gamma 7 interacts with the mRNA-binding protein heterogeneous nuclear ribonucleoprotein A2 and regulates the stability of specific mRNAs, including $\mathrm{Ca}_{\mathrm{V}} 2.2$. J Neurosci 28:10604-10617. CrossRef Medline

Geuens T, Bouhy D, Timmerman V (2016) The hnRNP family: insights into their role in health and disease. Hum Genet 135:851-867. CrossRef Medline

Hamdan FF, Srour M, Capo-Chichi JM, Daoud H, Nassif C, Patry L, Massicotte C, Ambalavanan A, Spiegelman D, Diallo O, Henrion E, DionneLaporte A, Fougerat A, Pshezhetsky AV, Venkateswaran S, Rouleau GA, Michaud JL (2014) De novo mutations in moderate or severe intellectual disability. PLoS Genet 10:e1004772. CrossRef Medline

Han SP, Tang YH, Smith R (2010) Functional diversity of the hnRNPs: past, present and perspectives. Biochem J 430:379-392. CrossRef Medline

Helbig I, Lowenstein DH (2013) Genetics of the epilepsies: where are we and where are we going? Curr Opin Neurol 26:179-185. CrossRef Medline

Heron SE, Smith KR, Bahlo M, Nobili L, Kahana E, Licchetta L, Oliver KL, Mazarib A, Afawi Z, Korczyn A, Plazzi G, Petrou S, Berkovic SF, Scheffer IE, Dibbens LM (2012) Missense mutations in the sodium-gated potassium channel gene KCNT1 cause severe autosomal dominant nocturnal frontal lobe epilepsy. Nat Genet 44:1188-1190. CrossRef Medline

Ishii A, Shioda M, Okumura A, Kidokoro H, Sakauchi M, Shimada S, Shimizu T, Osawa M, Hirose S, Yamamoto T (2013) A recurrent KCNT1 mutation in two sporadic cases with malignant migrating partial seizures in infancy. Gene 531:467-471. CrossRef Medline

Kaczmarek LK (2013) Slack, slick and sodium-activated potassium channels. ISRN Neurosci 2013:354262. CrossRef Medline

Kiledjian M, Dreyfuss G (1992) Primary structure and binding activity of the hnRNP U protein: binding RNA through RGG box. EMBO J 11:26552664. Medline

Kim H, Pierce-Shimomura JT, Oh HJ, Johnson BE, Goodman MB, McIntire SL (2009) The dystrophin complex controls BK channel localization and muscle activity in Caenorhabditis elegans. PLoS Genet 5:e1000780. CrossRef Medline

Kolisnyk B, Al-Onaizi MA, Xu J, Parfitt GM, Ostapchenko VG, Hanin G, Soreq H, Prado MA, Prado VF (2016) Cholinergic regulation of hnRNPA2/B1 translation by M1 muscarinic receptors. J Neurosci 36:62876296. CrossRef Medline

Li Q, Yan J (2016) Modulation of BK channel function by auxiliary beta and gamma subunits. Int Rev Neurobiol 128:51-90. CrossRef Medline

Lim HH, Park BJ, Choi HS, Park CS, Eom SH, Ahnn J (1999) Identification and characterization of a putative C. elegans potassium channel gene (Ce-slo-2) distantly related to $\mathrm{Ca}^{2+}$-activated $\mathrm{K}^{+}$channels. Gene 240:3543. CrossRef Medline

Liu G, Razanau A, Hai Y, Yu J, Sohail M, Lobo VG, Chu J, Kung SK, Xie J (2012) A conserved serine of heterogeneous nuclear ribonucleoprotein L (hnRNP L) mediates depolarization-regulated alternative splicing of potassium channels. J Biol Chem 287:22709-22716. CrossRef Medline

Liu P, Ge Q, Chen B, Salkoff L, Kotlikoff MI, Wang ZW (2011) Genetic dissection of ion currents underlying all-or-none action potentials in $C$. elegans body-wall muscle cells. J Physiol 589:101-117. CrossRef Medline
Liu P, Chen B, Wang ZW (2013) Postsynaptic current bursts instruct action potential firing at a graded synapse. Nat Commun 4:1911. CrossRef Medline

Liu P, Chen B, Wang ZW (2014) SLO-2 potassium channel is an important regulator of neurotransmitter release in Caenorhabditis elegans. Nat Commun 5:5155. CrossRef Medline

Lu R, Bausch AE, Kallenborn-Gerhardt W, Stoetzer C, Debruin N, Ruth P, Geisslinger G, Leffler A, Lukowski R, Schmidtko A (2015) Slack channels expressed in sensory neurons control neuropathic pain in mice. J Neurosci 35:1125-1135. CrossRef Medline

Lu S, Das P, Fadool DA, Kaczmarek LK (2010) The slack sodium-activated potassium channel provides a major outward current in olfactory neurons of Kv1.3 $3^{-1-}$ super-smeller mice. J Neurophysiol 103:3311-3319. CrossRef Medline

Martin HC, Kim GE, Pagnamenta AT, Murakami Y, Carvill GL, Meyer E, Copley RR, Rimmer A, Barcia G, Fleming MR, Kronengold J, Brown MR, Hudspith KA, Broxholme J, Kanapin A, Cazier JB, Kinoshita T, Nabbout R, Bentley D, McVean G, et al (2014) Clinical whole-genome sequencing in severe early-onset epilepsy reveals new genes and improves molecular diagnosis. Hum Mol Genet 23:3200-3211. CrossRef Medline

Martinez-Espinosa PL, Wu J, Yang C, Gonzalez-Perez V, Zhou H, Liang H, Xia XM, Lingle CJ (2015) Knockout of Slo2.2 enhances itch, abolishes $\mathrm{KNa}$ current, and increases action potential firing frequency in DRG neurons. Elife 4:e10013. CrossRef Medline

Matsuoka Y, Uehara N, Tsubura A (2009) hnRNP U interacts with the c-Myc-Max complex on the E-box promoter region inducing the ornithine decarboxylase gene. Oncol Rep 22:249-255. CrossRef Medline

Muslimov IA, Tuzhilin A, Tang TH, Wong RK, Bianchi R, Tiedge H (2014) Interactions of noncanonical motifs with hnRNP A2 promote activitydependent RNA transport in neurons. J Cell Biol 205:493-510. CrossRef Medline

Nagamani SC, Erez A, Bay C, Pettigrew A, Lalani SR, Herman K, Graham BH, Nowaczyk MJ, Proud M, Craigen WJ, Hopkins B, Kozel B, Plunkett K, Hixson P, Stankiewicz P, Patel A, Cheung SW (2012) Delineation of a deletion region critical for corpus callosal abnormalities in chromosome 1q43-q44. Eur J Hum Genet 20:176-179. CrossRef Medline

Roshon MJ, Ruley HE (2005) Hypomorphic mutation in hnRNP U results in post-implantation lethality. Transgenic Res 14:179-192. CrossRef Medline

Rozic G, Lupowitz Z, Zisapel N (2013) Exonal elements and factors involved in the depolarization-induced alternative splicing of neurexin 2 . J Mol Neurosci 50:221-233. CrossRef Medline

Schopperle WM, Holmqvist MH, Zhou Y, Wang J, Wang Z, Griffith LC, Keselman I, Kusinitz F, Dagan D, Levitan IB (1998) Slob, a novel protein that interacts with the Slowpoke calcium-dependent potassium channel. Neuron 20:565-573. CrossRef Medline

Selmer KK, Bryne E, Rødningen OK, Fannemel M (2012) A de novo $163 \mathrm{~kb}$ interstitial 1q44 microdeletion in a boy with thin corpus callosum, psychomotor delay and seizures. Eur J Med Genet 55:715-718. CrossRef Medline

Spraggon L, Dudnakova T, Slight J, Lustig-Yariv O, Cotterell J, Hastie N, Miles C (2007) hnRNP-U directly interacts with WT1 and modulates WT1 transcriptional activation. Oncogene 26:1484-1491. CrossRef Medline

Thierry G, Bénéteau C, Pichon O, Flori E, Isidor B, Popelard F, Delrue MA, Duboscq-Bidot L, Thuresson AC, van Bon BW, Cailley D, Rooryck C, Paubel A, Metay C, Dusser A, Pasquier L, Béri M, Bonnet C, Jaillard S, Dubourg C, et al (2012) Molecular characterization of 1q44 microdeletion in 11 patients reveals three candidate genes for intellectual disability and seizures. Am J Med Genet A 158A:1633-1640. CrossRef Medline

Vanderver A, Simons C, Schmidt JL, Pearl PL, Bloom M, Lavenstein B, Miller D, Grimmond SM, Taft RJ (2014) Identification of a novel de novo p.Phe932Ile KCNT1 mutation in a patient with leukoencephalopathy and severe epilepsy. Pediatr Neurol 50:112-114. CrossRef Medline

Vizlin-Hodzic D, Johansson H, Ryme J, Simonsson T, Simonsson S (2011) SAF-A has a role in transcriptional regulation of Oct4 in ES cells through promoter binding. Cell Reprogram 13:13-27. CrossRef Medline

Wang SJ, Wang ZW (2013) Track-A-Worm, an open-source system for quantitative assessment of $C$. elegans locomotory and bending behavior. PLoS One 8:e69653. CrossRef Medline

Wang ZW, Saifee O, Nonet ML, Salkoff L (2001) SLO-1 potassium channels control quantal content of neurotransmitter release at the C. elegans neuromuscular junction. Neuron 32:867-881. CrossRef Medline 
Wee CD, Havens MA, Jodelka FM, Hastings ML (2014) Targeting SR proteins improves SMN expression in spinal muscular atrophy cells. PLoS One 9:e115205. CrossRef Medline

Wei A, Yuan A, Fawcett G, Butler A, Davis T, Xu SY, Salkoff L (2002) Efficient isolation of targeted Caenorhabditis elegans deletion strains using highly thermostable restriction endonucleases and PCR. Nucleic Acids Res 30:e110. CrossRef Medline

Xia Xm, Hirschberg B, Smolik S, Forte M, Adelman JP (1998) dSLo interacting protein 1 , a novel protein that interacts with large-conductance calciumactivated potassium channels. J Neurosci 18:2360-2369. Medline

Xiao R, Tang P, Yang B, Huang J, Zhou Y, Shao C, Li H, Sun H, Zhang Y, Fu XD (2012) Nuclear matrix factor hnRNP U/SAF-A exerts a global control of alternative splicing by regulating U2 snRNP maturation. Mol Cell 45:656-668. CrossRef Medline

Ye J, Beetz N, O'Keeffe S, Tapia JC, Macpherson L, Chen WV, Bassel-Duby R, Olson EN, Maniatis T (2015) hnRNP U protein is required for normal pre-mRNA splicing and postnatal heart development and function. Proc Natl Acad Sci U S A 112:E3020-E3029. CrossRef Medline
Yuan A, Dourado M, Butler A, Walton N, Wei A, Salkoff L (2000) SLO-2, a $\mathrm{K}^{+}$channel with an unusual $\mathrm{Cl}^{-}$dependence. Nat Neurosci 3:771-779. CrossRef Medline

Yuan A, Santi CM, Wei A, Wang ZW, Pollak K, Nonet M, Kaczmarek L, Crowder CM, Salkoff L (2003) The sodium-activated potassium channel is encoded by a member of the Slo gene family. Neuron 37:765-773. CrossRef Medline

Yugami M, Kabe Y, Yamaguchi Y, Wada T, Handa H (2007) hnRNP-U enhances the expression of specific genes by stabilizing mRNA. FEBS Lett 581:1-7. CrossRef Medline

Zhang Y, Brown MR, Hyland C, Chen Y, Kronengold J, Fleming MR, Kohn AB, Moroz LL, Kaczmarek LK (2012) Regulation of neuronal excitability by interaction of fragile $\mathrm{X}$ mental retardation protein with slack potassium channels. J Neurosci 32:15318-15327. CrossRef Medline

Zhou Y, Schopperle WM, Murrey H, Jaramillo A, Dagan D, Griffith LC, Levitan IB (1999) A dynamically regulated 14-3-3, Slob, and Slowpoke potassium channel complex in Drosophila presynaptic nerve terminals. Neuron 22:809-818. CrossRef Medline 